\title{
Doses e épocas de aplicação de nitrogênio em cobertura na qualidade fisiológica de sementes de milho doce ${ }^{1}$
}

\author{
Claudemir Zucareli2*, Barbara Panoff ${ }^{3}$, Georggia Portugal'2, \\ Inês Cristina Batista Fonseca
}

\begin{abstract}
RESUMO - A quantidade e a época de aplicação de nitrogênio em cobertura podem favorecer a qualidade fisiológica das sementes, com o aumento do teor de proteína, que são importantes no desenvolvimento do embrião. Neste trabalho objetivou-se avaliar a qualidade fisiológica de sementes de milho doce provenientes de plantas cultivadas sob diferentes doses e épocas de aplicação de nitrogênio em cobertura. Foram utilizadas sementes da variedade $\mathrm{BR} 400$, provenientes de plantas submetidas às doses de $0,40,80$, e $120 \mathrm{~kg} \mathrm{ha}^{-1}$ de $\mathrm{N}$ aplicadas nos estádios vegetativo e reprodutivo. Foram determinadas a massa de 100 sementes, germinação, primeira contagem de germinação, a massa seca e o crescimento de plântulas, o vigor, pelos testes de frio, envelhecimento acelerado, emergência de plântulas no campo, tetrazólio, condutividade elétrica e índice de velocidade de emergência. Os dados foram submetidos à análise de variância pelo teste $\mathrm{F}$ a $5 \%$ e a estudo de regressão até $2^{\circ}$ grau. As doses e épocas de aplicação de nitrogênio em cobertura não afetaram a massa de sementes e a germinação das sementes de milho doce. O aumento da dose de $\mathrm{N}$ em cobertura, com aplicação no estádio vegetativo, reduziu o comprimento da parte aérea, de raiz e total das plântulas.
\end{abstract}

Termos para indexação: Zea mays, vigor, germinação, adubação nitrogenada tardia.

\section{Rates and time of nitrogen broadcasting on the physiological quality of sweet corn seed}

\begin{abstract}
The amount and timing of nitrogen application can favor seed quality, such as increasing protein content, which is an important constituent for embryo development. The objective of this study was to evaluate the physiological quality of sweet corn seeds collected from plants cultivated with different dosages and timings of nitrogen top-dressing applications. Seeds of the BR 400 variety (Super Sweet) were used obtained from plants submitted to dosages of $0,40,80$ and $120 \mathrm{~kg} \mathrm{ha}^{-1}$ of $\mathrm{N}$ in two top-dressing applications (vegetative and reproductive stages). The weight of 100 grains, germination, first count of germination test, dry weight of normal seedlings from the germination test, seedling growth, cold test, accelerated aging, tetrazolium vigor and electric conductivity and emergency speed rate were determined. Data was submitted to an analysis of variance using the F-test at the 5\% level and second degree regression analysis. The dosage and time of application of nitrogen top-dressing did not affect seed weight or the germination of sweet corn seeds. An increase of the $\mathrm{N}$ top-dressing dosage, applied in the vegetative stage reduced the length of the aerial part, the root and the whole seedling.
\end{abstract}

Index terms: Zea mays, vigor, germination, late nitrogen fertilization.

${ }^{1}$ Submetido em 14/07/2011. Aceito para publicação em 04/01/2012.

${ }^{2}$ Departamento de Agronomia, Universidade Estadual de Londrina (UEL), Caixa Postal 6001, 86001-970-Londrina, PR, Brasil.
${ }^{3}$ FAC / Universidade do Estado de São Paulo (UNESP), 18610-307-Botucatu, SP, Brasil.

*Autor para correspondência <claudemircca@ugl.br> 


\section{Introdução}

O milho doce (Zea mays L.) é classificado como milho especial e destina-se exclusivamente ao consumo humano. É utilizado principalmente como milho verde, tanto "in natura" como para processamento pelas indústrias de produtos vegetais em conserva (Oliveira Junior et al., 2006). O milho doce apresenta caráter adocicado, quando comparado com o milho comum, devido à presença de alelos mutantes que bloqueiam a conversão de açúcares em amido no endosperma. Por conter pouca reserva de amido no endosperma e pericarpo tenro, apresenta características indesejáveis, como baixa produtividade, assim como rápida perda de viabilidade das sementes, acarretando baixa uniformidade do stand no campo (Oliveira Junior et al., 2006). O pericarpo pouco espesso, qualidade desejável para o consumo, aumenta a ocorrência de danos mecânicos e facilita a entrada de patógenos, contribuindo dessa forma para a redução da germinação e do vigor das sementes.

Uma das premissas para obtenção de elevadas produtividades na cultura do milho é a utilização de sementes de qualidade (Popinigis, 1985). A formação de sementes na cultura do milho está estreitamente relacionada com a translocação de açúcares e de nitrogênio (Neumann et al., 2005; Duete et al., 2008) de órgãos vegetativos, principalmente das folhas e colmo, para as sementes. $\mathrm{Na}$ fase de enchimento de sementes as reservas desses órgãos são quebradas, translocadas e armazenadas nas sementes, na forma de proteínas e aminoácidos (Marschener, 1995).

A disponibilidade de $\mathrm{N}$ é um dos principais fatores limitantes ao crescimento e desenvolvimento das plantas (Meneghin et al., 2008). Segundo Lopes et al. (2004) o nitrogênio é o nutriente que mais limita o desenvolvimento, a produtividade e a biomassa da maioria das culturas. É também o nutriente absorvido em maiores quantidades pela maioria das culturas, especialmente as gramíneas.

A adubação nitrogenada influencia não só a produtividade, mas também a qualidade do produto em consequência do aumento do teor de proteína nas sementes que são constituintes importantes no desenvolvimento do embrião (Landry e Delye, 1993; Ferreira et al., 2001).

O nitrogênio é o nutriente mais difícil de ser manejado nos solos em virtude do grande número de reações a que está sujeito (Ernani, 2003). As recomendações relacionadas a dose e época de aplicação de nitrogênio na cultura do milho são divergentes e alvo de questionamento por parte dos pesquisadores. A recomendação clássica de $\mathrm{N}$ para milho é a aplicação de $1 / 3$ da dose de $\mathrm{N}$ na semeadura e
$2 / 3$ em uma ou duas aplicações de cobertura, quando as plantas estiverem com $40-60 \mathrm{~cm}$ de altura. Ou então, com base nos estádios fenológicos da cultura, ou seja, quando as plantas estiverem com quatro a oito folhas (Fancelli e Dourado-Neto, 2002) ou com seis a oito folhas totalmente expandidas (Vitti; Favarin, 1997 apud Ceretta, 1997).

Resultados obtidos por Rambo et al. (2004) avaliando o efeito da adubação nitrogenada tardiamente, na fase de espigamento, observaram resposta positiva no rendimento de grãos à aplicação de $\mathrm{N}$ nesta fase, sendo maior à medida que a deficiência de $\mathrm{N}$ no período vegetativo aumentou. Contudo, quando ocorreu deficiência de $\mathrm{N}$ no período vegetativo, o potencial de rendimento do milho já foi comprometido e não será mais atingido. Avaliando materiais genéticos, doses e épocas de aplicação de nitrogênio, Silva et al. (2005), concluiram que a resposta do rendimento à cobertura nitrogenada tardia diferiu entre as cultivares. Os aumentos no rendimento de sementes obtidos com coberturas tardias foram atribuídos principalmente a maior massa de grãos. Assim, a adubação tardia pode favorecer a quantidade de reservas acumuladas na sementes.

A qualidade fisiológica das sementes dos materiais genéticos responde diferentemente a diferentes doses de nitrogênio. Gondim et al. (2006) avaliando o efeito de diferentes níveis de nitrogênio no cultivo de variedades de milho sobre a qualidade fisiológica das sementes observaram que as sementes de todas as variedades apresentaram alta qualidade fisiológica quando cultivadas em altos níveis de nitrogênio. Contudo, quando em nível baixo de nitrogênio, observaram qualidade diferenciada das sementes das variedades. Para alguns materiais, o aumento da adubação nitrogenada propicia uma redução no vigor das sementes e aumento do número de plântulas anormais (Imolesi et al., 2001).

Os resultados de pesquisas referentes ao efeito do nitrogênio sobre a qualidade fisiológica das sementes são inconsistentes e, no que se refere à aplicação tardia de $\mathrm{N}$ e sua relação com a qualidade fisiológica de sementes, os estudos são escassos. Assim, o objetivo neste trabalho foi avaliar a qualidade fisiológica de sementes de milho doce provenientes de plantas cultivadas sob diferentes doses de nitrogênio em cobertura, aplicadas no estádio convencional (vegetativo) e tardio (reprodutivo).

\section{Material e Métodos}

O trabalho foi realizado no Laboratório de Análise de Sementes do Departamento de Agronomia da Universidade 
Estadual de Londrina, Londrina-PR. Foram utilizadas sementes de milho doce da variedade BR 400, pertencente ao grupo super doce, desenvolvida pela EMBRAPA, provenientes de plantas submetidas a diferentes doses de nitrogênio em cobertura $\left(0,40,80\right.$, e $120 \mathrm{~kg} \mathrm{ha}^{-1}$ de $\left.\mathrm{N}\right)$ e duas épocas de aplicação (vegetativa e reprodutiva). Na época vegetativa $\mathrm{o}$ $\mathrm{N}$ foi aplicado nos estádios V6 a V8 e na época reprodutiva no estádio R1, quando $75 \%$ das plantas apresentavam espigas com estigmas visíveis (Ritchie et al., 2003). A colheita das espigas foi realizada quando as sementes apresentavam teor de água de $20 \%$ e a debulha realizada manualmente.

O delineamento experimental utilizado foi inteiramente casualizado, em esquema fatorial $4 \times 2$, totalizando 8 tratamentos, com quatro repetições.

Para avaliação da qualidade física e fisiológica as sementes foram submetidas as seguintes determinações:

Massa de 1000 sementes: foi determinada empregandose 8 repetições de 100 sementes, em cada repetição, conforme as Regras para Análise de Sementes (Brasil, 1992).

Germinação: foi conduzido com quatro repetições de 50 sementes, em papel toalha umedecido na proporção de 2,5 vezes a massa (g) do substrato. Os rolos de papel, acondicionados em sacos plásticos, foram mantidos em germinador tipo câmera, na posição horizontal, sob temperatura de $30{ }^{\circ} \mathrm{C}$. As contagens foram realizadas aos quatro e sete dias após a instalação do teste, seguindo os critérios estabelecidos em (Brasil, 1992). Os resultados foram expressos em porcentagem.

Primeira contagem de germinação: constituiu na determinação, em porcentagem, das plântulas normais aos quatro dias após a instalação do teste de germinação.

Massa de matéria seca de plântulas: após a avaliação das plântulas normais, na primeira contagem do teste de germinação, estas foram separadas em duas porções, parte aérea e radicular e, desse modo, acondicionadas em sacos de papel, levadas a estufa a $60 \pm 5^{\circ} \mathrm{C}$ até atingirem massa constante. Após as pesagens, em balança com precisão de 0,001 g, obteve-se a massa seca que, dividida pelo número de plântulas, expressou os resultados em gramas por plântula das porções aérea, radicular e total (Nakagawa, 1999).

Teste de crescimento de plântulas: foi utilizado quatro repetições de 10 sementes submetidas a germinação em papel toalha umedecido numa proporção de 2,5 vezes o seu peso seco. Os rolos foram mantidos em posição vertical, em germinador previamente regulado a $30{ }^{\circ} \mathrm{C}$, com ausência de luz, durante quatro dias. Após o período no germinador, estas foram separadas em duas porções, parte aérea e radicular e, desse modo, mediu-se o comprimento, expressando os resultados em centímetros por plântulas da parte aérea e radicular (Dias e Barros, 1995).

Teste de frio: foi conduzido utilizando-se a metodologia do rolo de papel sem solo, com quatro repetições de 50 sementes. As sementes foram colocadas entre papel toalha umedecido na proporção 2,5 vezes a massa (g) do substrato, conforme realizado no teste de germinação. Após a semeadura os rolos, colocados no interior de sacos plásticos vedados, permaneceram por sete dias em câmara regulada a $10{ }^{\circ} \mathrm{C}$ e, posteriormente, foram transferidos para outra câmara a $30{ }^{\circ} \mathrm{C}$, por mais quatro dias, após os quais se efetuou a contagem das plântulas normais, com os resultados expressos em porcentagem.

Envelhecimento acelerado: foram utilizadas quatro repetições de 65 sementes distribuídas em camada única, sobre bandeja de tela metálica fixada no interior de caixa plástica contendo $40 \mathrm{~mL}$ de água. As caixas, tampadas e acondicionadas em sacos plásticos foram mantidas a $42^{\circ} \mathrm{C}$ por 72 horas (Dias e Barros, 1995). Após este período, quatro repetições de 15 sementes foram submetidas a determinação do teor de água seguindo metodologia já relatada e, quatro repetições de 50 sementes foram submetidas ao teste de germinação. A avaliação foi realizada quatro dias após a instalação do teste, computando-se a porcentagem de plântulas normais.

Emergência de plântulas no campo: foram utilizadas 100 sementes por repetição, semeadas em sulcos de 5,0 $\mathrm{m}$ de comprimento, a profundidade de $2,5 \mathrm{~cm}$. Após a semeadura, o sulco foi coberto e a irrigação realizada toda vez que o solo mostrava-se seco. Após o início da emergência das plântulas, foram feitas contagens diárias, até a paralisação da emergência das plântulas, com os resultados expressos em porcentagem.

Teste de tetrazólio: foi conduzido empregando-se quatro repetições de 50 sementes que após pré-condicionadas em papel toalha umedecido com água destilada por 16 horas a $30{ }^{\circ} \mathrm{C}$, foram seccionadas, longitudinalmente e medianamente, através do embrião, descartando-se uma das partes. Em seguida, as amostras foram imersas em solução de tetrazólio $0,1 \%$ e mantidas em estufas a $35^{\circ} \mathrm{C}$ por 3 horas no escuro. Após a coloração das sementes a solução foi drenada, as sementes lavadas e mantidas imersas em água até a avaliação. Os resultados de vigor foram obtidos pelas médias das sementes pertencentes à classe 1, conforme metodologia descrita por (Dias e Barros, 1995).

Teste de condutividade elétrica: para esta avaliação, quatro repetições de 25 sementes, com massa conhecida, foram colocadas para embeber em $75 \mathrm{~mL}$ de água destilada, por um período de 24 horas a $25^{\circ} \mathrm{C}$ (Dias e Barros, 1995); 
seguiu-se leve agitação e leitura da condutividade elétrica da solução de embebição em condutivimetro, previamente calibrado, com eletrodo de constante 1,0 expressando os resultados em $\mu \mathrm{S} \mathrm{cm}^{-1} \mathrm{~g}^{-1}$ de sementes.

Índice de velocidade de emergência das plântulas no campo: utilizando-se o teste de emergência das plântulas no campo, foram realizadas contagens diárias, a partir da emergência da primeira plântula até o décimo quarto dia. O índice de velocidade de emergência (IVE) foi calculado segundo (Maguire, 1962; Nakagawa, 1999).

Os dados obtidos foram submetidos a análise de variância pelo teste $\mathrm{F}$ a $5 \%$ de probabilidade e, os dados de doses fora submetidos a estudo de regressão até $2^{\circ}$ grau.

\section{Resultados e Discussão}

Na Tabela 1 são apresentados os parâmetros cuja interação entre os fatores épocas e doses de aplicação de nitrogênio em cobertura não foram significativos. Não foram observados, também, efeitos de doses de $\mathrm{N}$ aplicada em cobertura para médias da massa de 100 sementes, germinação, primeira contagem do teste de germinação, plântulas anormais, sementes mortas, massa seca de raiz, massa seca da parte aérea, massa seca total, envelhecimento acelerado, emergência de plântulas no campo e índice de velocidade de emergência de plântulas de sementes de milho doce da cultivar BR 400 .

Tabela 1. Médias da massa de 100 sementes, germinação, primeira contagem de germinação, plântulas anormais, sementes mortas, massa seca de raiz, massa seca da parte aérea, massa seca total, envelhecimento acelerado, emergência de plântulas no campo e índice de velocidade de emergência de plântulas de sementes de milho doce da cultivar BR 400 em função de épocas de aplicação e doses de nitrogênio em cobertura.

\begin{tabular}{|c|c|c|c|c|c|c|c|}
\hline \multirow{3}{*}{ Parâmetros } & \multirow{2}{*}{\multicolumn{4}{|c|}{$\frac{\text { Doses de Nitrogênio em cobertura }}{\left(\mathrm{kg} \mathrm{ha}^{-1}\right)}$}} & \multirow{2}{*}{\multicolumn{2}{|c|}{ Épocas }} & \multirow{3}{*}{$\mathrm{CV} \%$} \\
\hline & & & & & & & \\
\hline & 0 & 40 & 80 & 120 & Vegetativo & Reprodutivo & \\
\hline Massa de 100 sementes (g) & 13 & 14 & 13 & 14 & 13 & 13 & 2,37 \\
\hline Germinação (\%) & 79 & 72 & 76 & 75 & 76 & 75 & 8,36 \\
\hline Primeira contagem do teste germinação (\%) & 11 & 13 & 12 & 13 & 13 & 12 & 35,02 \\
\hline Plântulas anormais (\%) & 8 & 8 & 8 & 7 & 8 & 7 & 56,19 \\
\hline Sementes mortas $(\%)$ & 3 & 7 & 5 & 6 & $3 \mathrm{a}$ & $7 \mathrm{~b}$ & 75,99 \\
\hline Massa seca de raiz (g) & 0,011 & 0,010 & 0,010 & 0,011 & 0,010 & 0,011 & 13,98 \\
\hline Massa seca da parte aérea (g) & 0,17 & 0,15 & 0,15 & 0,26 & 0,016 & 0,16 & 22,11 \\
\hline Massa seca total (g) & 0,29 & 0,27 & 0,27 & 0,28 & 0,27 & 0,29 & 15,61 \\
\hline Envelhecimento acelerado (\%) & 84 & 87 & 84 & 86 & $86 \mathrm{a}$ & $84 \mathrm{~b}$ & 8,49 \\
\hline Emergência de plântulas no campo (\%) & 56 & 53 & 65 & 59 & $66,38 \mathrm{a}$ & $50,63 \mathrm{~b}$ & 27,79 \\
\hline Índice de velocidade de emergência & 9 & 7 & 8 & 8 & $7 \mathrm{~b}$ & $9 \mathrm{a}$ & 21,08 \\
\hline
\end{tabular}

Médias seguidas de letras iguais na linha não diferem pelo teste $\mathrm{F}$ a 5\%.

Cícero et al. (1979) avaliando cultivares de milho e níveis de fertilidade de solo quanto à qualidade das sementes, observaram não haver relação dos níveis de fertilidade do solo com a germinação das sementes, corroborando com os resultados obtidos, onde as doses de $\mathrm{N}$ em cobertura não beneficiaram a germinação das sementes de milho doce. Não se constatou efeitos de doses e épocas de aplicação de nitrogênio na primeira contagem do teste de germinação, resultado também obtido por Lopes et al., (2004) em funções de doses e tipos de adubações nitrogenadas.

A massa de 100 sementes é um parâmetro importante para a determinação da produção de milho doce. Porém, não foi constatado benefícios neste trabalho, em relação às doses de nitrogênio utilizadas em cobertura. Meire et al., (2009) não constataram diferenças na massa das sementes quando utilizado a dose de $120 \mathrm{~kg} \mathrm{ha}^{1}$ de nitrogênio em cobertura em milho irrigado. No entanto, Bono (2008) constata diferenças significativas positivas com um aumento na massa das sementes, em relação à aplicação de doses de $120 \mathrm{~kg} \mathrm{ha}^{1}$ de nitrogênio em cobertura em milho comum.

Entre as épocas de aplicação de nitrogênio foram observados efeitos significativos para algumas variáveis analisadas (Tabela 1). A aplicação de $\mathrm{N}$ na época vegetativa resultou em menor porcentagem de sementes mortas e maior porcentagem de plântulas normais no teste de envelhecimento acelerado e maior porcentagem de emergência de plântulas no 
campo. Quando o nitrogênio foi aplicado na época reprodutiva, constatou-se maior índice de velocidade de emergência de plântulas no campo. Segundo Cavalcante et al. (1982), o efeito de fertilizantes pode acarretar diferenças fisiológicas em sementes, como o aumento do vigor, em consequência da ação dos nutrientes em algumas enzimas na semente.

Não foram constatadas diferenças significativas em relação às doses de nitrogênio aplicadas em cobertura no milho doce para o teste de envelhecimento acelerado e de emergência de plântulas no campo. No entanto, para o teste de envelhecimento acelerado, Gondin et al. (2006) verificaram que variedades de milho comum, apresentaram alto vigor quando aplicadas doses altas de nitrogênio e baixo vigor quando aplicado doses baixas de nitrogênio em cobertura. Em trabalho realizado por Imolesi et al. (2001), foi observado diferença significativa no índice de velocidade de emergência em função a doses de nitrogênio aplicadas, diferentemente do presente trabalho que foi em relação às épocas de aplicação.

Na Tabela 2 são apresentados os parâmetros avaliados cuja interação entre os fatores épocas e doses de aplicação de nitrogênio em cobertura foram significativos. Em todos os parâmetros avaliados (médias de comprimento da parte aérea, comprimento de raíz, comprimento total, teste de frio, tetrazólio vigor e condutividade elétrica) para a dose de 0 $\mathrm{kg}$ ha- ${ }^{1}$, não houve diferença significativa entre as épocas de aplicação de $\mathrm{N}$ em cobertura, resultado este já esperado, pois em ambos os casos não houve aplicação de $\mathrm{N}$.

Tabela 2. Médias de comprimento da parte aérea, comprimento de raiz, comprimento total, teste de frio, tetrazólio vigor e condutividade elétrica de sementes de milho doce da cultivar BR 400 em função de épocas de aplicação e doses de nitrogênio em cobertura.

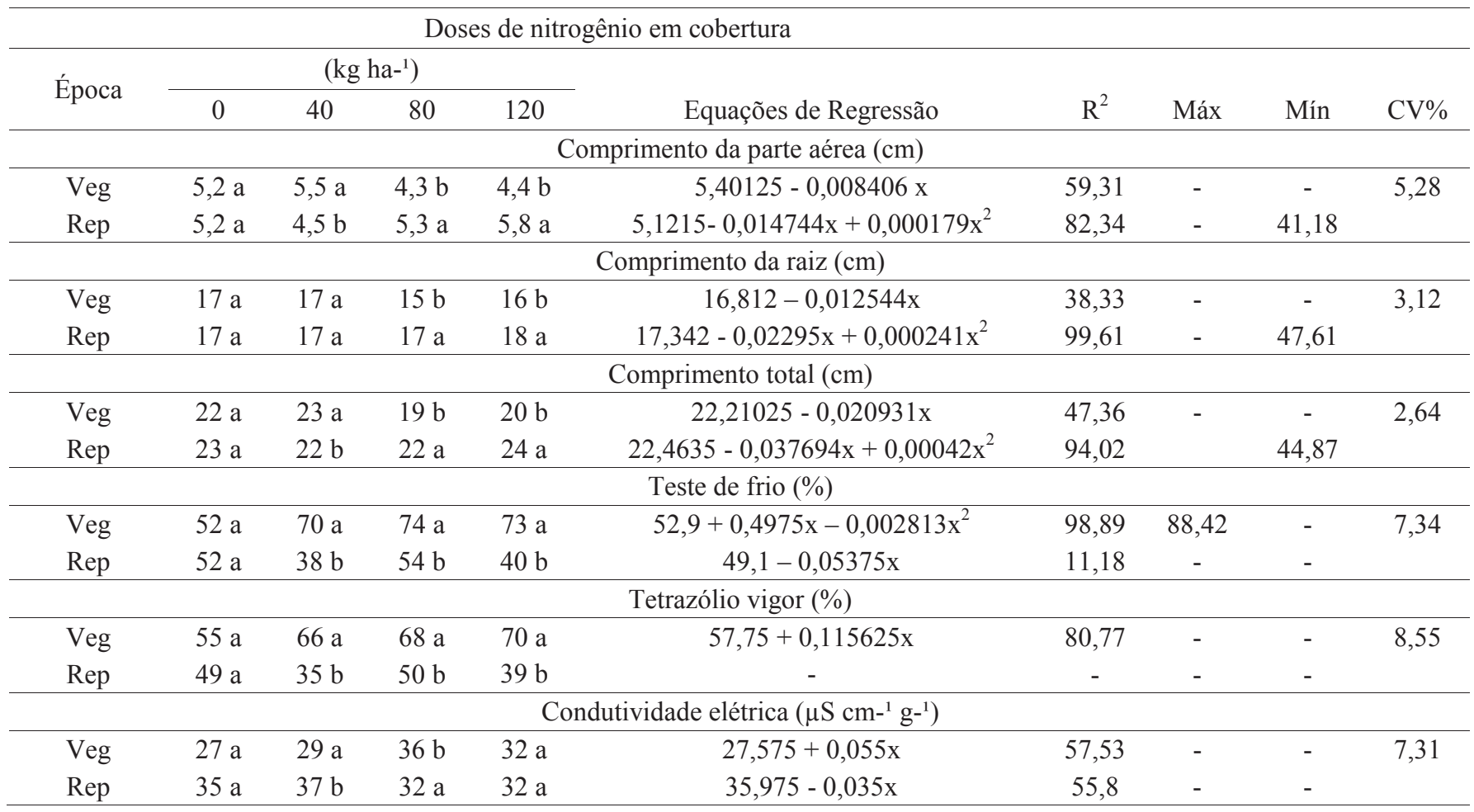

Médias seguidas de letras iguais na coluna não diferem pelo teste $\mathrm{F}$ a $5 \%$.

Veg = aplicação de nitrogênio em cobertura no estádio vegetativo;

Rep = aplicação de nitrogênio em cobertura no estádio reprodutivo

Para o comprimento da parte aérea do teste de crescimento de plântulas, houve diferença significativa entre épocas de aplicação de nitrogênio em cobertura, com resultados superiores quando o $\mathrm{N}$ foi aplicado na época vegetativa na dose de $40 \mathrm{Kg} \mathrm{ha}^{-1}$ de N. Contudo, maiores comprimentos da parte aérea do teste de crescimento de plântulas, foram obtidos quando o nitrogênio foi aplicado em cobertura na época reprodutiva nas doses de 80 e $120 \mathrm{Kg} \mathrm{ha}^{-1}$ de N. Em relação às doses de $\mathrm{N}$ estudadas, quando a aplicação em cobertura foi realizada na época vegetativa os resultados de comprimento 
da parte aérea ajustaram-se a uma equação linear com resposta decrescente ao incremento das doses, no entanto, quando a aplicação de nitrogênio em cobertura foi realizada na época reprodutiva os dados se ajustaram a uma função quadrática pelo estudo de regressão (Figura $1 \mathrm{~A}$ ), com dose de mínima estimada em 41,18 Kg ha-1 de N (Tabela 2).

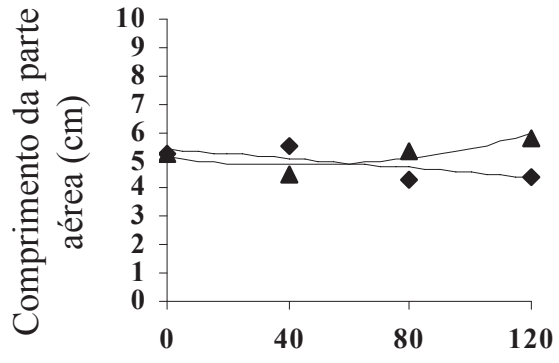

(A)

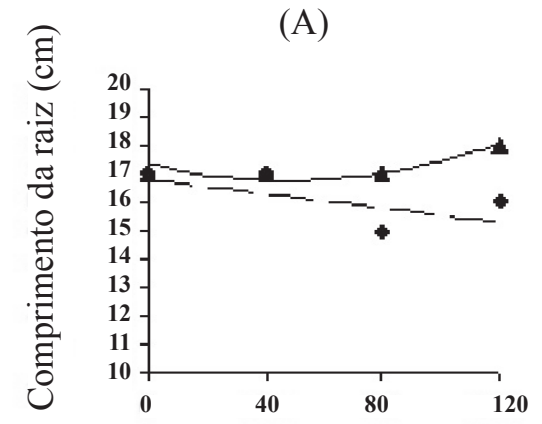

(B)

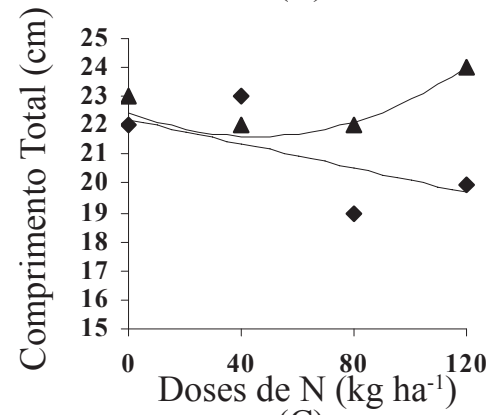

(C)

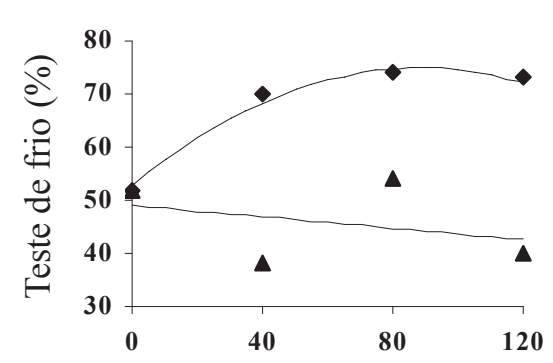

(D)

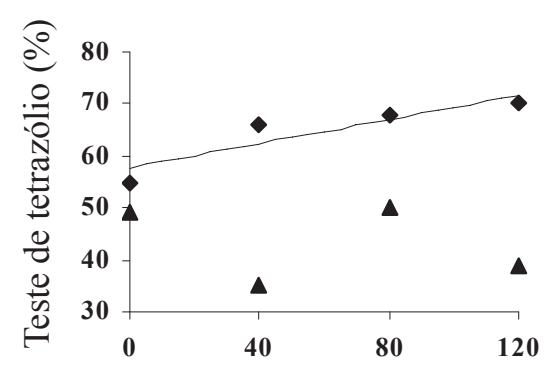

(E)

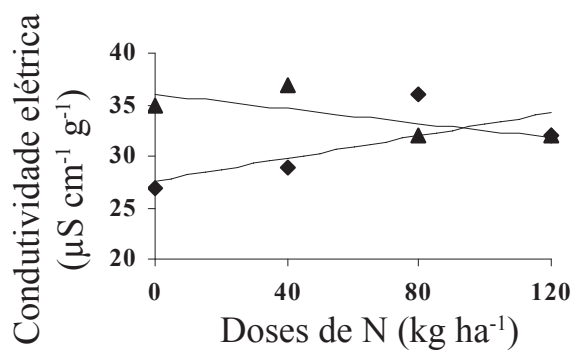

(F)

Figura 1.Comprimento da parte aérea (A), comprimento de raiz (B), comprimento total (C), teste de frio (D), tetrazólio vigor $(\mathrm{E})$, condutividade elétrica $(\mathrm{F})$ de milho doce da cultivar BR 400 em função de doses de nitrogênio em cobertura em duas épocas de aplicação (- - - - - vegetativa e reprodutiva).

Para comprimento de raiz de plântulas do teste de crescimento de plântulas, não se constatou diferença significativa entre épocas de aplicação de nitrogênio em cobertura quando se utilizou $40 \mathrm{Kg}$ ha $^{-1}$ de $\mathrm{N}$. Houve diferença significativa entre épocas de aplicação com maiores comprimentos de raiz de plântulas quando a aplicação de nitrogênio foi realizada na época reprodutiva para as doses de 80 e $120 \mathrm{Kg} \mathrm{ha}^{-1}$ de N (Tabela 2). Quando a aplicação de N em cobertura foi realizada na época vegetativa os resultados em função de doses se ajustaram a uma equação linear com resposta decrescente, e quando a aplicação de nitrogênio foi realizada na época reprodutiva os dados se ajustaram a uma função quadrática (Figura $1 \mathrm{~B}$ ), sendo $47,61 \mathrm{Kg} \mathrm{ha}^{-1}$ de $\mathrm{N}$ a dose de mínima estimada (Tabela 2).

Para comprimento total de plântulas do teste de crescimento de plântulas, as épocas avaliadas apresentaram diferenças significativas para as doses 40,80 e $120 \mathrm{Kg}$ $\mathrm{ha}^{-1}$ de $\mathrm{N}$, com maiores valores quando a aplicação foi realizada na época vegetativa utilizando $40 \mathrm{~kg} \mathrm{~N}$ ha $^{-1} \mathrm{e}$ quando a aplicação foi realizada na época reprodutiva com 80 e $120 \mathrm{~kg} \mathrm{~N} \mathrm{ha}^{-1}$ (Tabela 2). Em relação às doses de nitrogênio, quando a aplicação foi realizada na época 
vegetativa os dados do comprimento total ajustaram-se a uma equação linear decrescente e, quando a aplicação foi realizada na época reprodutiva os dados se ajustaram a uma função quadrática (Figura 1C), estimando-se a dose mínima em 44,87 kg N ha-1 (Tabela 2).

Para o teste de frio foi constatado diferenças significativas entre épocas de aplicação de nitrogênio em cobertura, sendo que a maior porcentagem de plantas normais no teste de frio foi obtida quando o nitrogênio foi aplicado na época vegetativa. $O$ nitrogênio aplicado na época reprodutiva propiciou menor germinação em todas as doses utilizadas. Na Figura 1D observa-se que quando a aplicação de nitrogênio foi realizada na época vegetativa os dados se ajustaram a uma função quadrática pelo estudo de regressão, estimando-se uma maior porcentagem de plantas germinadas após o teste de frio quando utilizada uma dose de $88,42 \mathrm{~kg} \mathrm{~N} \mathrm{ha}^{-1}$ (Tabela 2). Para a época reprodutiva a equação ajustada foi linear com resposta decrescente com o incremento das doses de $\mathrm{N}$ utilizadas em cobertura. Resultados obtidos por Gondin et al. (2006) em relação a doses de nitrogênio aplicadas em relação a variedades de milho comum no teste de frio, apresentam uma melhor qualidade nas sementes quando aplicado doses altas de nitrogênio. No entanto, Imolesi et al. (2001) não observou diferenças significativas na porcentagem de geminação de milho comum após o teste de frio em função de doses de nitrogênio aplicadas em cobertura.

Para o vigor avaliado pelo teste de tetrazólio, as épocas de aplicação de $\mathrm{N}$ em cobertura apresentaram diferenças significativas, com maior vigor quando o $\mathrm{N}$ foi aplicado na época vegetativa para as doses 40, 80 e $120 \mathrm{~kg} \mathrm{ha}^{-1}$. Em relação às doses de nitrogênio estudadas, quando a aplicação foi realizada na época vegetativa, os dados se ajustaram a uma equação linear crescente e, não houve efeito de dose quando a aplicação foi realizada na época reprodutiva (Figura $1 \mathrm{E}$ ).

$\mathrm{O}$ teste de condutividade elétrica, não detectou diferenças no vigor das sementes em função de épocas de aplicação de nitrogênio em cobertura quando se utilizou a dose $120 \mathrm{~kg} \mathrm{~N} \mathrm{ha}^{-1}$. Contudo, na dose de $40 \mathrm{~kg}$ $\mathrm{N} \mathrm{ha}^{-1}$ a aplicação na época vegetativa e na de $80 \mathrm{~kg} \mathrm{~N}$ $\mathrm{ha}^{-1}$ a aplicação na época reprodutiva propiciaram menor lixiviação de eletrolíticos, resultando em menores valores de condutividade elétrica e, consequentemente, sementes de maior vigor. Em relação às doses de $\mathrm{N}$ estudadas, os valores da condutividade elétrica se ajustaram a uma equação linear crescente e decrescente para as aplicações realizadas na época vegetativa e reprodutiva, respectivamente (Figura $1 \mathrm{~F}$ ).
A magnitude das respostas da cultura de milho a aplicação de nitrogênio em ensaios conduzidos no Brasil são bastante variadas (Pereira Filho e Cruz, 2002)e, os resultados referentes ao efeito do nitrogênio na qualidade fisiológica das sementes tem se mostrado inconsistente (Imolesi t al., 2001).

\section{Conclusões}

As doses e épocas de aplicação de nitrogênio em cobertura não afetam a massa e a germinação de sementes de milho doce.

A aplicação de $\mathrm{N}$ no estádio vegetativo favorece o vigor das sementes de milho doce.

$\mathrm{O}$ aumento da dose de $\mathrm{N}$ em cobertura, com aplicação no estádio vegetativo, reduz o comprimento da parte aérea, de raiz e total de plântulas de milho doce.

\section{Referências}

BONO, J.A.M. Modo de aplicação de fertilizantes nitrogenados na qualidade fisiológica de sementes de milho. Agrarian, v.1, n.2, p.91-102, out./dez. 2008. http://www.periodicos.ufgd.edu.br/index.php/agrarian/ article/viewArticle/258

BRASIL. Ministério da Agricultura e Reforma Agrária. Regras para análise de sementes. Secretaria Nacional de Defesa Agropecuária. Departamento Nacional de Produção Vegetal. Coordenação de Laboratório Vegetal. Brasília, DF, 1992. 365p.

CAVALCANTE, J.I.V; SILVEIRA, J.F.; VIEIRA, M.G.G.C. Influência do nitrogênio, fósforo,potássio e zinco na germinação e vigor de sementesde arroz. Revista Brasileira de Sementes, v.4, n.3, p.27-33, 1982. http://www.abrates.org.br/revista/artigos/1982/v4n3/artigo03.pdf

CERETTA, C.A. Manejo da adubação nitrogenada no sistema plantio direto. In: Atualização em recomendação de adubação $e$ calagem - ênfase em plantio direto. Santa Maria: Departamento de solosCCR-UFSM-Núcleo regional Sul, 1997. p.112-124.

CÍCERO, S.M.; TOLEDO, F.F.; CAMPOS, H. Efeitos da fertilidade do solo sobre a produção a germinação e o vigor das sementes de milho. Revista Brasileira de Sementes, v.2, n.1, p.13-23, 1979. http://www. abrates.org.br/revista/artigos/1979/v1n2/artigo02.pdf

DIAS, M.C.L.L.; BARROS, A.S.R. Avaliação da qualidade de sementes de milho. Londrina: IAPAR, 1995. 43p.

DUETE, R.R.C.; MURAOKA,T.; SILVA, E.C.; TRIVELIN, P.C.O.; AMBROSANO, E.J. Manejo da adubação nitrogenada e utilização do nitrogênio (15n) pelo milho em latossolo vermelho. Revista Brasileira de Ciência do Solo. 32:161-171, 2008.

ERNANI, P.R. Disponibilidade de nitrogênio e adubação nitrogenada 
para a macieira. Lages: Graphel, 2003. 76p.

FANCELLI, A.L.; DOURADO-NETO, D. Produção de milho. Guaíba: Ed. Agropecúaria, 2002. 360p.

FERREIRA, A.C.B.; ARAÚJO, G.A. A.; PEREIRA, P.R.G.; CARDOSO, A.A.; Características agronômicas e nutricionais do milho adubado com nitrogênio, molibdênio e zinco. Scientia Agrícola, v.58, n.1, p.131-138, jan./mar. 2001. http://www.scielo.br/pdf/sa/v58n1/a20v58n1.pdf

GONDIM, T.C.O.; ROCHA.; V.S.; SANTOS, M.M.; MIRANDA, G.V. Avaliação da qualidade fisiológica de sementes de milho crioulo sob estresse causado por baixo nível de nitrogênio. Revista Ceres, p.413-417 2006. http://www.ceres.ufv.br/CERES/revistas/V53N307P05906.pdf

IMOLESI, A.S.; VON PINHO, E.V.R.; VON PINHO, R.G.; VIEIRA, M.G.G.C.; CORRÊA, R.S.B. Influência da adubação nitrogenada na qualidade fisiológica das sementes de milho. Ciência Agrotecnologia, v.25, n.5, p.1119-1126, 2001. http://www.editora.ufla.br/site/_adm/ upload/revista/25-5-2001_10.pdf

LANDRY, J.; DELYE, S. The Tryptopn contents of wheat, maize and barley grains as a function of nitrogen content. Journal of Cereal Science, v.18, p.259-266, 1993.

LOPES, H.M.; GALVÃO, J.C.C.; DAVID, A.M.S.S.; ALMEIDA, A.A.; ARAÚJO, E.F.; MOREIRA, L.B.; MIRANDA, G.V. Qualidade física e fisiológica de sementes de milho em função da adubação mineral e orgânica. Revista Brasileira de Milho e Sorgo, v.3, n.2, p.265-275, 2004. http://rbms.cnpms.embrapa.br/index.php/ojs/article/viewArticle/107

MAGUIRE, J.D. Speeds of germination-aid and evaluation for seedling emergence and vigor. Crop Science, v.2, n.2, p.176-7, 1962.

MARSCHENER, H. Mineral nutrition of higher plant. 2.ed. New York: Academic Press, 1995. 889p.

MEIRE, F.A.; BUZETTI, S.; ANDREOTTI, M.; ARF, O.; ANDRADE, J.A.C. Fontes e épocas de aplicação de nitrogênio na cultura do milho irrigado. Ciências Agrárias, v.30, n.2, p.275-284, 2009.

MENEGHIN, M.F.S.; RAMOS, M.L.G.; OLIVEIRA, S.A.; RIBEIRO JUNIOR, W.Q.; AMÁBILE, R.F. Avaliação da disponibilidade de nitrogênio para o trigo, em solo do Distrito Federal. Revista Brasileira de Ciência do Solo, v.32, p.1941-1948, 2008. http://redalyc.uaemex.mx/src/ inicio/ArtPdfRed.jsp?iCve=180214065015
NEUMANN, M.; SANDINI, I.E.; LUSTOSA, S.B.C.; OST, P.R; ROMANO, M.A.; FALBO, M.K.; PANSERA, E.R. Rendimentos e componentes de produção da planta de milho (Zea mays l.) para silagem, em função de níveis de adubação nitrogenada em cobertura. Revista Brasileira de Milho e Sorgo. v.4, n.3, p.418-427, 2005. http://rbms. cnpms.embrapa.br/index.php/ojs/article/viewArticle/161

NAKAGAWA, J. Testes de vigor baseados no desempenho de plântulas. In: KRZYZANOWSKI, F.C., VIEIRA, R.D., FRANÇA-NETO, J.B. Vigor de sementes: conceitos e testes. Londrina: ABRATES, 1999. p.2.1-2.24.

OLIVEIRA JUNIOR, L.F.G.; DELIZA, R.; BRESSAN-SMITH, R.; PEREIRA, M.G.; CHIQUIERE, T.B. Seleção de genótipos de milho mais promissores para o consumo in natura. Ciência e Tecnologia de Alimentos, v.26, n.1, p.159-165, 2006. http://www.scielo.br/scielo. php?pid=S0101-20612006000100026\&script=sci_arttext

PEREIRA FILHO, I.A.; CRUZ, J.C. Cultivares de milho para o consumo verde. Sete Lagoas: Embrapa Milho e Sorgo, jan., 2002. p.1-7 (Circular Técnica, n.15). http://www.infoteca.cnptia.embrapa.br/bitstream/ doc/485443/1/Circ15.pdf

POPINIGIS, F. Fisiologia da semente. 2.ed. Brasília, DF: AGIPLAN, 1985. 289p.

RAMBO, L.; SILVA, P.R.F.; ARGENTA, G.; BAYER, C. Testes de nitrato no solo como indicadores complementares no manejo da adubação nitrogenada em milho. Ciência Rural, v.34, n.4, p.1279-1287, 2004. http://redalyc.uaemex.mx/src/inicio/ArtPdfRed.jsp?iCve=33134454

RITCHIE, S. W.; HANWAY, J.; BENSON, G. O. Como a planta de milho se desenvolve. Arquivo do Agrônomo Potafos, n.103, p.1-20, 2003. http://www.potafos.org/ppiweb/brazil.nsf/87cb8a98bf72572b8525693e0 053ea70/7759ddc6878ca7eb83256d05004c6dd1/\$FILE/Encarte103.pdf

SILVA, P.R.F.; STRIEDER, M.L.; COSE, R.P.S.; RAMBO, L.; SANGOI, L.; ARGENTA, G.; FORSTHOFER, E. L.; SILVA, A.A. Rendimento e teor de proteína bruta nos grãos de híbridos de milho com adubação nitrogenada de cobertura tardia. Scientia Agrícola, v.62, n.5, p.487-492, 2005. http://www.scielo.br/pdf/sa/v62n5/25991.pdf 